\title{
Bacterial Infection Induces Nitric Oxide Synthase in Human Neutrophils
}

Marcia A. Wheeler, ${ }^{\star}$ Shannon D. Smith, ${ }^{*}$ Guillermo García-Cardeña, ${ }^{\ddagger}$ Carl F. Nathan,,${ }^{\S}$ Robert M. Weiss, ${ }^{*}$ and William C. Sessa ${ }^{\ddagger}$

$*$ Department of Surgery, Section of Urology, ${ }^{\ddagger}$ Department of Pharmacology, Section of Molecular Cardiobiology, Yale University School of Medicine, New Haven, Connecticut 06520; and ${ }^{\S}$ Division of Hematology-Oncology, Cornell University Medical College, New York 10021

\begin{abstract}
The identification of human inflammatory cells that express inducible nitric oxide synthase and the clarification of the role of inducible nitric oxide synthase in human infectious or inflammatory processes have been elusive. In neutrophilenriched fractions from urine, we demonstrate a 43 -fold increase in nitric oxide synthase activity in patients with urinary tract infections compared with that in neutrophilenriched fractions from noninfected controls. Partially purified inducible nitric oxide synthase is primarily membrane associated, calcium independent, and inhibited by arginine analogues with a rank order consistent with that of purified human inducible nitric oxide synthase. Molecular, biochemical, and immunocytochemical evidence unequivocally identifies inducible nitric oxide synthase as the major nitric oxide synthase isoform found in neutrophils isolated from urine during urinary tract infections. Elevated inducible nitric oxide synthase activity and elevated nitric oxide synthase protein measured in patients with urinary tract infections and treated with antibiotics does not decrease until 6-10 d of antibiotic treatment. The extended elevation of neutrophil inducible nitric oxide synthase during urinary tract infections may have both antimicrobial and proinflammatory functions. (J. Clin. Invest. 1997. 99:110-116.) Key words: leukocytes • urinary tract infection • inflammation • immunocytochemistry $\bullet$ nitric oxide
\end{abstract}

\section{Introduction}

In rodent macrophages and neutrophils, inducible nitric oxide synthase $(\mathrm{iNOS})^{1}$ produces large quantities of nitric oxide (NO) that can modulate immune, inflammatory and cardiovascular responses $(1,2)$. Even though much effort has been expended on the development of iNOS-selective inhibitors as therapeutic agents $(3,4)$, the role of iNOS in human infectious

A preliminary report of this work was presented at Experimental $\mathrm{Bi}$ ology, 14-17 April 1996, Washington, DC.

Address correspondence to Robert M. Weiss, Yale University School of Medicine, Department of Surgery/Section of Urology, P.O. Box 208041, New Haven, CT 06520-8041. Phone: 203-785-2815; FAX: 203-785-4043.

Received for publication 17 May 1996 and accepted in revised form 15 October 1996

1. Abbreviations used in this paper: eNOS, endothelial nitric oxide synthase; iNOS, inducible NOS; RT-PCR, reverse transcriptase PCR; UTI, urinary tract infection.

J. Clin. Invest.

(C) The American Society for Clinical Investigation, Inc. 0021-9738/97/01/0110/07 \$2.00

Volume 99, Number 1, January 1997, 110-116 and inflammatory processes is poorly understood. Despite some evidence suggesting the presence of iNOS in human macrophages, nitric oxide synthase (NOS) in human neutrophils is not well characterized. Early reports indicate that human neutrophils can generate small amounts of NO (5) and may contain both a constitutive NOS (6) and an NO-sensitive guanylyl cyclase $(7,8)$. More recent studies have failed to detect either constitutive or inducible NOS activity (9).

Previously, we found that particulate, NADPH-dependent, calcium-independent NOS activity is elevated in urine of patients with bacterial urinary tract infections (UTIs) (10). During bacterial infection, high levels of several cytokines $(11,12)$ are secreted by the uroepithelial cells and a large number of inflammatory cells, primarily neutrophils infiltrate the bladder. Since large numbers of neutrophils are found in urine from many patients with UTIs (13) this disease represents an opportunity to evaluate NOS in human neutrophils during infectious and/or inflammatory processes. Therefore, the goals of the present study are to identify the NOS isoform(s) in urinary leukocytes, to characterize the NOS expressing cells, and to examine NOS during the course of infection.

\section{Methods}

Sample acquisition. Both clean catch and catheterized urines were collected from control patients $(n=16,75 \%$ female; average age, $60.5 \pm 5.2 \mathrm{yr}$ old; age range, $25-75 \mathrm{yr}$ old $)$ and patients with UTIs $(n=$ $40,82 \%$ female; average age, $52.5 \pm 3.7 \mathrm{yr}$ old; age range $21-80 \mathrm{yr}$ old). To obtain sufficient leukocytes for assay, control urines that were selected, contained $<10^{4} \mathrm{CFU} / \mathrm{ml}$, and were negative for nitrite and positive for leukocyte esterase. Nitrite and leukocyte esterase were determined on whole urine using LN 2 Chemstrips (Boehringer Mannheim Biochemicals, Indianapolis, IN). Contributing factors in patients with a positive leukocyte esterase test and a negative urine culture included: kidney transplantation $(n=2)$, pregnancy $(n=3)$, Foley catheter drainage $(n=4)$, candida vaginitis $(n=1)$, bladder carcinoma $(n=1)$, appendicial abscess $(n=1)$, large residual urine volume $(n=1)$, and interstitial cystitis $(n=3)$. Of the bacterially infected urines collected, $>10^{5} \mathrm{CFU} / \mathrm{ml}$ of the following organisms were cultured: Escherichia coli (55\%), Klebsiella spp (15\%), Pseudomonas aeruginosa (10\%), Staphylococcus spp (5\%), and other (15\%). E. coli, Klebsiella spp, and Enterococcus isolated from urine cultures grown on blood and MacConkey agar plates also were used as controls.

Neutrophil membrane preparation and solubilization of iNOS activity. Pellets isolated from whole urine by centrifugation (400 $\mathrm{g}, 5$ min, $4^{\circ} \mathrm{C}$ ) were resuspended in PBS, underlayered with Ficoll-sodium diatrizoate (LSM, Organon Teknika Corp, Durham, NC) and centrifuged $\left(400 \mathrm{~g}, 20 \mathrm{~min}, 4^{\circ} \mathrm{C}\right)$ to isolate an activated population of neutophils. The cells adherent to the side of the tube contained $92 \pm 5 \%$ leukocytes, while the cells in the pellet contained $90 \pm 6 \%$ leukocytes $(n=5)$. The vast majority of these cells are neutrophils as determined by microscopic analysis of the preparations after Papanicolau staining. No significant difference in NOS activity or immunoreactivity was seen between these two fractions. Neutrophil-enriched fractions were resuspended in PBS, centrifuged $\left(400 \mathrm{~g}, 5 \mathrm{~min}, 4^{\circ} \mathrm{C}\right)$, and 
resuspended in an ice-cold homgenization buffer ( 1 vol pellet/10 vol buffer) which consisted of $20 \mathrm{mM}$ Hepes (pH 7.2), $1.0 \mathrm{mM}$ DTT, 0.05 $\mathrm{mM}$ phenylmethylsulfonyl fluoride, leupeptin $(0.2 \mathrm{mg} / 100 \mathrm{ml})$ and 1.0 $\mathrm{mg} / 100 \mathrm{ml}$ of soybean trypsin inhibitor, pepstatin, antipain, and chymostatin (Buffer H). The resuspended pellet was homogenized with an Ultra-turrax T25 (IKA Labortechnik, Staufen, Germany) and centrifuged $\left(20,000 \mathrm{~g}, 20 \mathrm{~min}, 4^{\circ} \mathrm{C}\right)$. The membrane fraction was stored at $-80^{\circ} \mathrm{C}$ until assay. Membranes were resuspended and washed two times to remove exogenous L-arginine and cofactors.

For partial purification of NOS, membranes prepared from urinary pellets from infected patients were extracted at $4^{\circ} \mathrm{C}$ with $0.8 \%$ deoxycholate in buffer $\mathrm{H}$ containing $10 \%$ glycerol (buffer A). Lysates were centrifuged $\left(50,000 \mathrm{~g}\right.$ for $40 \mathrm{~min}$ at $\left.4^{\circ} \mathrm{C}\right)$ and supernatants were passed over a 1-ml column of 2', 5' ADP-Sepharose (Pharmacia LKB Biotechnology, Uppsala, Sweden). The column was washed with buffer A containing $200 \mathrm{mM} \mathrm{NaCl}$ and then with buffer A containing $2 \mathrm{mM} \mathrm{NADP}^{+}$. NOS was eluted with $10 \mathrm{mM}$ NADPH.

NOS activity assays. NOS activity was measured in crude membranes from neutrophil-enriched fractions and in solubilized, partially purified column eluates. NOS activity was measured $\left(45 \mathrm{~min}, 37^{\circ} \mathrm{C}\right)$ as the formation of $\left[{ }^{14} \mathrm{C}\right]$-L-citrulline from $\left[{ }^{14} \mathrm{C}\right]$-L-arginine $(3 \mu \mathrm{M})$ in a reaction mix containing: $2 \mathrm{mM} \mathrm{NADPH}, 1 \mathrm{mM} \mathrm{CaCl}_{2}, 10 \mathrm{mM}$ valine, $10 \mu \mathrm{M}$ FAD and $10 \mu \mathrm{M}$ tetrahydrobiopterin. L-citrulline was eluted from AG 50W-X8 ( $\mathrm{Na}^{+}$-form) (Bio-Rad, Hercules, CA) and $\left[{ }^{14} \mathrm{C}\right]-\mathrm{L}-$ citrulline was quantified by liquid scintillation counting. The enzyme was diluted so that $<25 \%$ of $\left[{ }^{14} \mathrm{C}\right]-\mathrm{L}$-arginine was hydrolyzed. Thin layer chromatography of the radioactive products of the NOS activity assay showed that $82-97 \%$ of the radioactivity migrated as citrulline (10). Protein concentrations were measured using gamma globulin as standard with the Bradford Assay (14).

Reverse transcriptase (RT)-PCR of iNOS and endothelial NOS (eNOS) from neutrophil-enriched leukocytes. Total RNA was isolated from neutrophil enriched pellets using Trisolve reagent (Life Technologies, Inc., Gaithersburg, MD). Single stranded cDNA was synthesized using oligo dT priming and Superscript II Reverse-Transcriptase (Gibco-BRL, Life Technologies, Gaithersburg, MD). In preliminary studies, using generalized human NOS primers (sense $5^{\prime}-\mathrm{AC}^{\mathrm{T}} / \mathrm{CCC}^{\mathrm{T}} / \mathrm{GTT}^{\mathrm{G}} / \mathrm{T}_{\mathrm{TT}}^{\mathrm{T}} / \mathrm{TCA}_{\mathrm{T}}^{\mathrm{C}} / \mathrm{T}$ CAGGAG-3 ${ }^{\prime}$ and antisense $5^{\prime}-\mathrm{CT}$ $\left.\mathrm{G}^{\mathrm{G}} / \mathrm{CCC}^{\mathrm{A}} / \mathrm{G}_{\mathrm{G}} \mathrm{C}^{\mathrm{A}} / \mathrm{T}_{\mathrm{T}} /{ }_{\mathrm{G}} \mathrm{AGCTC} / \mathrm{A} / \mathrm{TC}_{\mathrm{G}} / \mathrm{CC}-3^{\prime}\right)$, PCR amplified products from human iNOS, eNOS, and neuronal NOS cDNAs. However, Southern blotting of PCR products from neutrophil enriched pellets detected only human iNOS and eNOS products, but not neuronal NOS products (data not shown). Human iNOS specific primers for subsequent PCR analysis were: sense 5'-CACCTTTGATGAGGGGAC-3' and antisense 5'-GCATCCAGCTTGACCAG-3'. Human eNOS specific primers were: sense 5'-GTGATGGCGAAGCGAGTGAAG-3' and antisense 5'-CCGAGCCCGAACACACAGAAC-3' (15). As a control for cDNA synthesis, $\beta$-actin specific primers (sense 5'-AGCGGGAAATCGTGCGTG-3' and antisense 5'-CAGGGTACATGGTGGTGCC-3') were used (15). PCR products were electrophoresed on $1 \%$ agarose gels and stained with ethidium bromide. The resultant PCR products were $413 \mathrm{bp}$ for iNOS and $422 \mathrm{bp}$ for eNOS. NOS isoform-specific primers did not amplify the other forms of NOS (i.e., iNOS-specific primers did not amplify human eNOS nor neuronal NOS cDNAs).

Western analysis. Laemmli sample buffer was added to total cell lysates, membranes or 2', 5' ADP-Sepharose purified iNOS and samples were heated to $95^{\circ} \mathrm{C}$ for $10 \mathrm{~min}$. Proteins were electrophoresed on $7.5 \%$ gels by SDS-PAGE, (16) transferred to nitrocellulose and blotted with human iNOS specific polyclonal antisera $(1: 30,000)(17)$, eNOS-specific monoclonal antisera $(1: 1,000)(18)$ or neuronal NOS antisera (1:1,500; Transduction Labs, Lexington, KY). A goat, antirabbit Ig conjugated to horseradish peroxidase (Amersham International, Buckinghamshire, United Kingdom) was used as a secondary antibody for iNOS and a goat, anti-mouse conjugated to horseradish peroxidase (Amersham International) was used as a secondary antibody for eNOS. Immunoreactive proteins were detected with the enhanced chemiluminescence method (Amersham International).
Leukocyte isolation and immunocytochemistry. Cell pellets from fresh nitrite positive, leukocyte esterase positive urines were incubated with CD45 (Anti-HLe-1) monoclonal antibody or with CD14 (LEU-M3) monoclonal antibody (Becton Dickinson, San Jose, CA) (100 $\mu$ l antibody/75 $\mu \mathrm{l}$ packed pellet) in PBS containing protease inhibitor cocktail (Boehringer Mannheim Biochemicals) and $0.1 \%$ BSA, (PBS A) for $30 \mathrm{~min}\left(4^{\circ} \mathrm{C}\right)$. The CD45 antigen is present on all human leukocytes, while the CD14 antigen is present on the majority of normal peripheral blood monocytes. The antibodies were removed by centrifugation (three times with PBS A, $700 \mathrm{~g}, 3 \mathrm{~min}$ ) and cells were incubated with fluorescein isothiocyanate labeled anti-mouse IgG (FITC, 1:150) in PBS A for $30 \mathrm{~min}\left(4^{\circ} \mathrm{C}\right)$. In control cells, the CD45 antibody was omitted. Cells were sorted by flow cytometry, centrifuged onto slides $(1,200 \mathrm{rpm}, 5 \mathrm{~min})$, and fixed with acetone $\left(-20^{\circ} \mathrm{C}\right)$ for $10 \mathrm{~min}$.

For iNOS colocalization studies, the CD45 labeled, flow cytometry-sorted cells were permeabilized with $0.1 \%$ Triton X-100 for 3 min, extensively washed in PBS A and incubated sequentially with iNOS polyclonal antibody $(1: 1,000)$ for $2 \mathrm{~h}$ at room temperature and Texas Red anti-rabbit IgG for $1 \mathrm{~h}$ at room temperature. Cells were washed three times after each incubation. Slides were mounted with Slowfade (Molecular Probes, Eugene, OR) and photographed using a Nikon Microphot -FXA microscope (Lake Success, NY). The specificity of the iNOS antibody was determined by preabsorption of the antisera with the immunogen peptide (YRASLEMSAL-COOH) and by the lack of staining with the secondary anti sera alone.

Data analysis. $\mathrm{IC}_{50} \mathrm{~s}$ were determined using a computer assisted $\log$-logit plot $(n=$ two to six experiments performed in duplicate for each inhibitor) and curves were constructed using a curve fitting program. Results were expressed as mean \pm SEM and means were compared usings analysis of variance followed by the Fisher F-test. Multicomparison significance level was $95 \%$.

\section{Results}

To identify the NOS isoform(s) present and to characterize the cell types expressing NOS activity, we performed Ficoll density gradient fractionation of cell pellets isolated from patients with UTIs. The majority of NOS activity is found in neutrophilenriched fractions, i.e., the adherent fraction and the cell pellet. Differential staining of leukocyte subsets confirmed the enrichment with neutrophils in the NOS-positive fractions. NADPH-dependent NOS activity is 43-fold higher in neutrophil-enriched fractions isolated from urines obtained from patients with UTIs compared with that in neutrophil-positive urines obtained from patients without UTIs $(23.5 \pm 13.8[n=11]$ and $0.55 \pm 0.16[n=8] \mathrm{pmol}$ citrulline $/ \mathrm{mg}$ protein per min, respectively). The leukocyte NOS activity is inhibited competitively by the following inhibitors with a rank order of: $\mathrm{L}-N^{5}-(1-$ iminoethyl)ornithine (L-NIO) $>$ L-thiocitrulline $>N^{\mathrm{G}}$-monomethyl-L-arginine (L-NMMA) $>$ L-canavanine $>$ aminoguanidine $>N^{\mathrm{G}}$-nitroarginine methyl ester (L-NAME) $=N^{\mathrm{G}}$-nitro-Larginine (L-NNA) (Fig. $1 A$, Table I). Leukocyte iNOS activity is inhibited by the calmodulin antagonists, trifluoperazine (TFP) and $N$-(6-aminohexyl)-5-chloro-1-naphthalene-sulfonamide (W-7) (Table I).

Deoxycholate $(0.8 \%)$ solubilizes $60 \%$ of NOS activity from membranes and is more effective than other detergents (CHAPS [10-20 mM], NP-40 [1\%], or Triton X-100 [0.1-1\%]). Solubilized NOS activity binds to the affinity resin, $2^{\prime} 5^{\prime}$ ADPSepharose, and is eluted with NADPH (10 mM). This detergent solubilized, semipurified NOS is calcium independent and shares the same inhibitor profile as the crude leukocyteenriched fraction (Fig. $1 \mathrm{~B}$ ). 

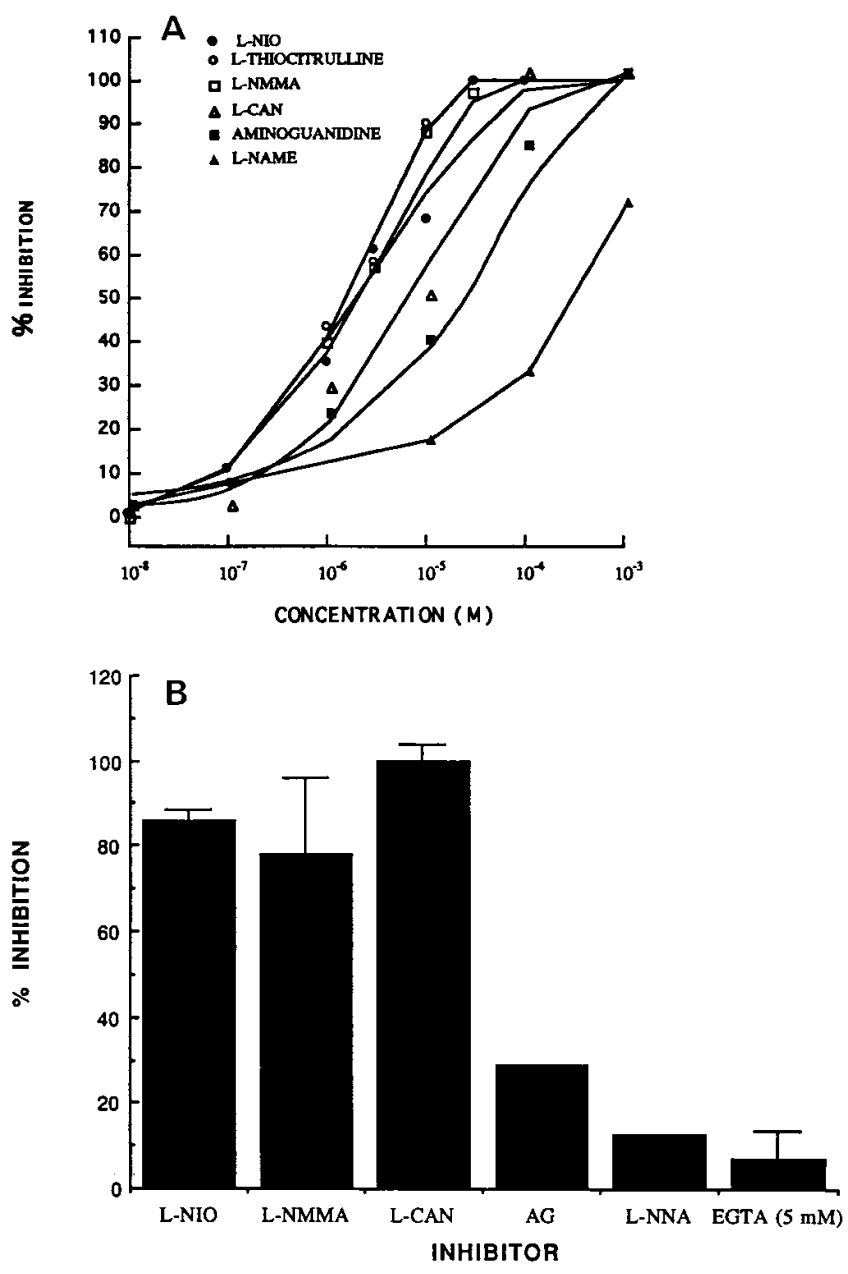

Figure 1. Inhibition of neutrophil-enriched $(A)$ or semi-purified $(B)$ NOS activity by arginine analogues decreases leukocyte NOS activity. $(A)$ Average iNOS values are given in the text. Data are expressed as percentage inhibition of control \pm SEM for two to three experiments for each inhibitor. Protein concentration of neutrophilenriched fractions was $0.45 \pm 0.08 \mathrm{mg} / \mathrm{ml}$ protein. $(B)$ Column eluates were assayed for NOS activity in the presence of $\mathrm{CaCl}_{2}$ (control), inhibitors $(100 \mu \mathrm{M})$ plus $\mathrm{CaCl}_{2}$ or EGTA ( $5 \mathrm{mM}$, no exogenous $\mathrm{CaCl}_{2}$ ).

To molecularly identify the NOS isoform(s) in urine from patients with UTIs, using oligonucleotide primers based on human iNOS and human endothelial NOS (eNOS), we performed RT-PCR on cDNA prepared from leukocyte-enriched total RNA. Fig. 2 reveals a specific 413 bp fragment consistently amplified with human iNOS primers. iNOS primer specific RT-PCR products were found in the eight urines with $>10^{5} \mathrm{CFU} / \mathrm{ml}$ of $E$. coli $(n=4)$, Enterococcus $(n=1)$, Pseudomonas $(n=1)$, Klebsiella $(n=1)$, or Enterobacter $(n=1)$. In the same samples, a faint RT-PCR product is seen using eNOS primers. DNA sequencing of the PCR products reveals $99.9 \%$ nucleotide sequence identity with their respective cloned human cDNAs. No primer specific RT-PCR product for iNOS was seen in samples prepared from three strains of bacteria.

Next, we used immunological criteria to characterize the iNOS activity in leukocyte enriched pellets using a specific $\mathrm{COOH}$ terminal human iNOS polyclonal antibody (17). Western blotting of total lysates or 2'5'ADP-Sepharose purified samples isolated from leukocyte enriched fractions obtained
Table I. NOS Inhibitors and Calmodulin Antagonists Inhibit Leukocyte NOS Activity

\begin{tabular}{lr}
\hline & $\mathrm{IC}_{50}$ \\
\hline NOS inhibitor & $\mu M$ \\
L-NIO & 3.0 \\
L-Thiocitrulline & 4.1 \\
L-NMMA & 7.1 \\
L-Canavanine & 12.1 \\
Aminoguanidine & 22.0 \\
L-NAME & 116 \\
L-NNA & $>200$ \\
Calmodulin antagonist & \\
Trifluoperizine & 10 \\
W-7 & 39 \\
\end{tabular}

$\mathrm{IC}_{50}$ values are determined using a computer-assisted log-logit plot for two to six experiments for each inhibitor, each done in duplicate.

from patients with UTIs identified immunoreactive iNOS protein at $\sim 130 \mathrm{kD}$, identical in $M_{\mathrm{r}}$ to the protein product seen in HEK 293 cells stably transfected with the human hepatocyte iNOS cDNA (Fig. 3, $A$ and $B$ ). No iNOS immunoreactivity is found in leukocyte enriched lysates, that are leukocyte positive, but nitrite and culture negative $(n=4$, Fig. $3 A)$ or in $2^{\prime} 5^{\prime}$ ADP-Sepharose purified samples $(n=4)$ prepared from leukocytes from control patients. Fig. $3 B$ shows that detergent solubilized and ADP-Sepharose purified iNOS from a patient infected with Pseudomonas aeruginosa was not detected after $6 \mathrm{~d}$ of antibiotic treatment. Preabsorption of the antisera with the immunogen peptide (YRASLEMSAL-COOH) eliminates the iNOS immunoreactivity in the total cell lysate and in ADPSepharose fractions as well as in transfected HEK 293 cells (data not shown). Using a specific eNOS monclonal antibody and using bovine eNOS expressed in HEK 293 cells as a positive control, eNOS protein is undetectable by Western blot analysis (18) in six samples that are positive for human iNOS either by Western blotting or by RT-PCR. These samples included two total cell lysates, two leukocyte-enriched lysates and two detergent-solubilized and $2^{\prime} 5^{\prime}$ ADP-Sepharose purified samples. Neither iNOS, neuronal NOS, nor eNOS protein was detected in $0.8 \%$ deoxycholate extracts from three strains of bacteria which were $2^{\prime} 5^{\prime}$ ADP-Sepharose purified.

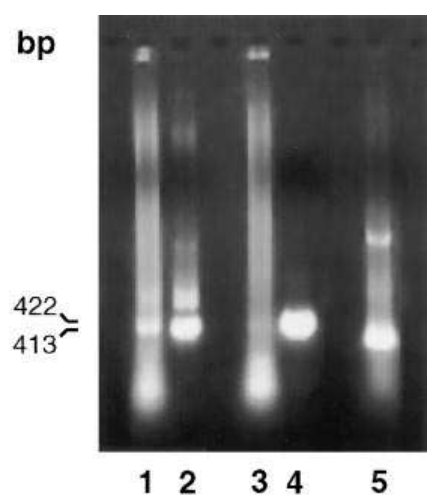

Figure 2. RT-PCR detects iNOS and ENOS mRNA in neutrophils from patients with UTIs. Single stranded cDNA prepared from NOS positive neutrophils was used as a template for RT-PCR with iNOS (lane 1) and eNOS (lane 3) specific primers. Lanes 2 and 4 show positive controls using human iNOS and eNOS cDNAs as PCR templates. iNOS and eNOS PCR products were 413 and $422 \mathrm{bp}$, respectively. $\beta$-actin is shown in lane 5 . 
A

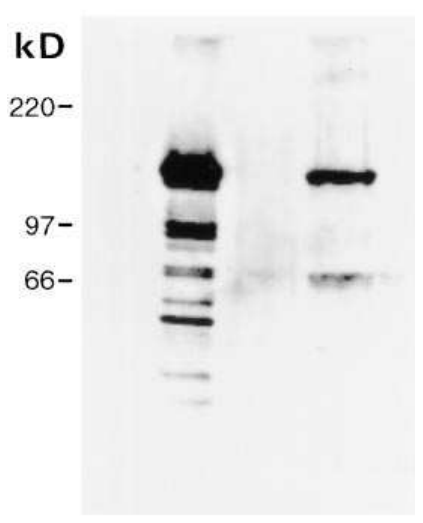

$\begin{array}{llll}1 & 2 & 3 & 4\end{array}$

B

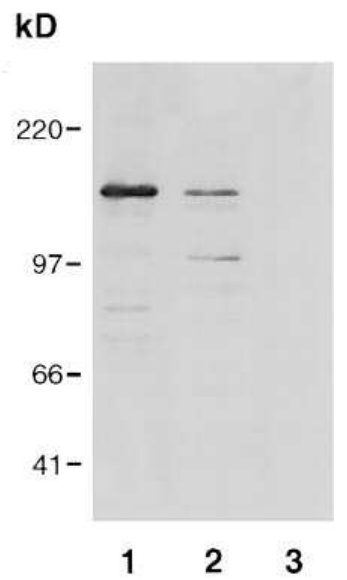

NOS Activity (pmol citrulline/ $\mathrm{min} / \mathrm{mg}$ prot.)

$\begin{array}{ll}7.4 & 0.9\end{array}$
Figure 3. Immunological detection of iNOS in human neutrophils isolated from patients with UTIs. Western blot anaysis was performed on the following samples: $(A)$ Equivalent amounts of total cell lysates from nontransfected HEK 293 cells (lane 1) and HEK 293 cells stably transfected with the human iNOS cDNA (lane 2), a leukocyteenriched fraction $(100 \mu \mathrm{g}$ protein) from a leukocyte-positive urine which showed no growth by culture (lane 3 ), a leukocyte-enriched fraction (100 $\mu \mathrm{g}$ protein) from a nitrite and leukocyte-positive urine with $>10^{5}$ CFU Pseudomonas (lane 4); (B) Detergent solubilized and ADP-Sepharose purified NOS from HEK 293 cells stably transfected with the human iNOS cDNA (lane 1), a leukocyte-enriched fraction $(260 \mu \mathrm{g}$ protein) prepared from a patient infected with $>10^{5}$ CFU Pseudomonas aeruginosa (leukocyte and nitrite positive) (lane 2), and a leukocyte-enriched fraction (280 $\mu$ g protein) prepared from the same patient after 6 $\mathrm{d}$ of antibiotic treatment (lane 3). NOS activity was measured in membrane fractions prepared from each sample. After antibiotic treatment, the urine was leukocyte positive but bacterial growth negative by culture. NOS activity was measured in membrane fractions prepared from each sample.

To determine which cell(s) contained iNOS, cells from patients with UTIs were fluorescently labeled with CD45, sorted by flow cytometry and the CD45 labeled cells were then incubated with iNOS antibody and a fluorescent probe. CD45 antigen is present on all human leukocytes. FACS sorting demonstrates that $86-93 \%(n=3)$ of the total fluorescent labeling is found in the CD45 positive peak (Fig. $4 \mathrm{~A}$ ), indicating that the vast majority of cells in patients with UTIs are leukocytes. CD14, a specific marker for human monocytes/macrophages, labels $6 \pm 3 \%$ of cells, indicating that the predominant population of CD45-labeled cells are neutrophils. Phase contrast microscopy confirmed that $>90 \%$ of these cells were neutrophils. After FACS cell sorting of CD45 labeled cells (Fig. 4 B), immunocytochemistry with iNOS antibody (Fig. $4 C$ ) demonstrates iNOS protein in $82.1 \pm 2.9 \%$ of the CD45-labeled cells ( $n=10$ fields, from three separate experiments) the vast majority of which are neutrophils. iNOS appears to be localized primarily in the perinuclear region of the CD45-positive neutophils (Fig. 4 C).

Neutrophil iNOS activity and protein were analyzed in urine pellets from patients at the time of UTI diagnosis and during the course of antibiotic treatment. In patients with UTIs, average NOS activity in total cell pellet was $10.7 \pm 2.9$ pmol citrulline/mg protein per $\min (n=5)$ at the time of diagnosis, and $23.5 \pm 8.6 \mathrm{pmol}$ citrulline/mg protein per $\min (n=5)$ after 2-4 d of antibiotic treatment. In these same patients, iNOS activity decreased significantly to $1.5 \pm 0.5$ pmol citrulline/mg protein per $\min (n=5) 6-17 \mathrm{~d}$ after the diagnosis and initiation of treatment of the UTI. These results are confirmed by Western blot analysis in $5 / 5$ patients; iNOS protein remains elevated after 2-4 d of antibiotic therapy, but is significantly reduced thereafter (Fig. 5).

\section{Discussion}

The present study identifies neutrophils as the primary source of iNOS in leukocyte-enriched pellets isolated from the urines of patients with UTIs. It is the first demonstration of biologically active iNOS in human neutrophils isolated during an infectious process. No NOS activity nor immunoreactivity was seen in 16/16 control samples of leukocyte-positive, culturenegative urine (Table II). This agrees with our previous report that NOS activity was significantly lower in 10/10 cell pellets from healthy controls that were leukocyte and urine culture negative compared to cell pellets from patients with UTIs (10). iNOS is markedly elevated in neutrophils (45/48 assays) isolated from the urine of patients (39/40) with UTIs compared with control patients (Table II). NOS activity was not elevated in a single patient with sickle cell anemia, sarcoidosis, and chronic renal failure receiving immunosuppressant therapy who had a history of persistant bacterial (Enterococcus and Klebsiella) and fungal infections.

The rank order of potency of NOS inhibitors on crude and semipurified neutrophil iNOS is consistent with that seen with human recombinant iNOS activity (19) where L-NMMA and L-NIO are equipotent and both are much more potent than aminoguanidine. L-NNA is a less potent inhibitor of human recombinant iNOS than of human recombinant eNOS or neuronal NOS. In activated rat peritoneal neutrophils, L-NIO and L-NMMA have a higher potency in inhibiting iNOS than does L-NNA (20). The $\mathrm{IC}_{50}$ s for L-NMMA and L-NIO are similar for human and rat neutrophil NOS and for human recombinant iNOS, while the $\mathrm{ED}_{50}$ for L-NNA is similar for human and rat neutrophil NOS but is higher than that for human recombinant iNOS. Unlike iNOS isolated from rodent sources, human neutrophil iNOS is inhibited by the calmodulin antagonists, TFP and W-7, suggesting that calmodulin is bound less tightly to the human enzyme relative to the rodent form. Indeed, calmodulin is associated tightly, but noncovalently, with purified murine iNOS (21). The affinity of calmodulin binding for human iNOS is presently not known. Irrespective of the potential differences in calmodulin binding affinity to human and rodent iNOS, both enzymes are clearly calcium independent (22).

NOS isolated from rat polymorphonuclear neutrophils (23) and iNOS isolated from transformed macrophages are primarily soluble proteins (24). Approximately $40 \%$ of iNOS isolated from primary mouse peritoneal macrophages (25) and $25 \%$ of the iNOS in the cloned murine macrophage cell line RAW264.7 are membrane associated (26). In contrast, $>90 \%$ of human neutrophil iNOS is tightly membrane associated, 

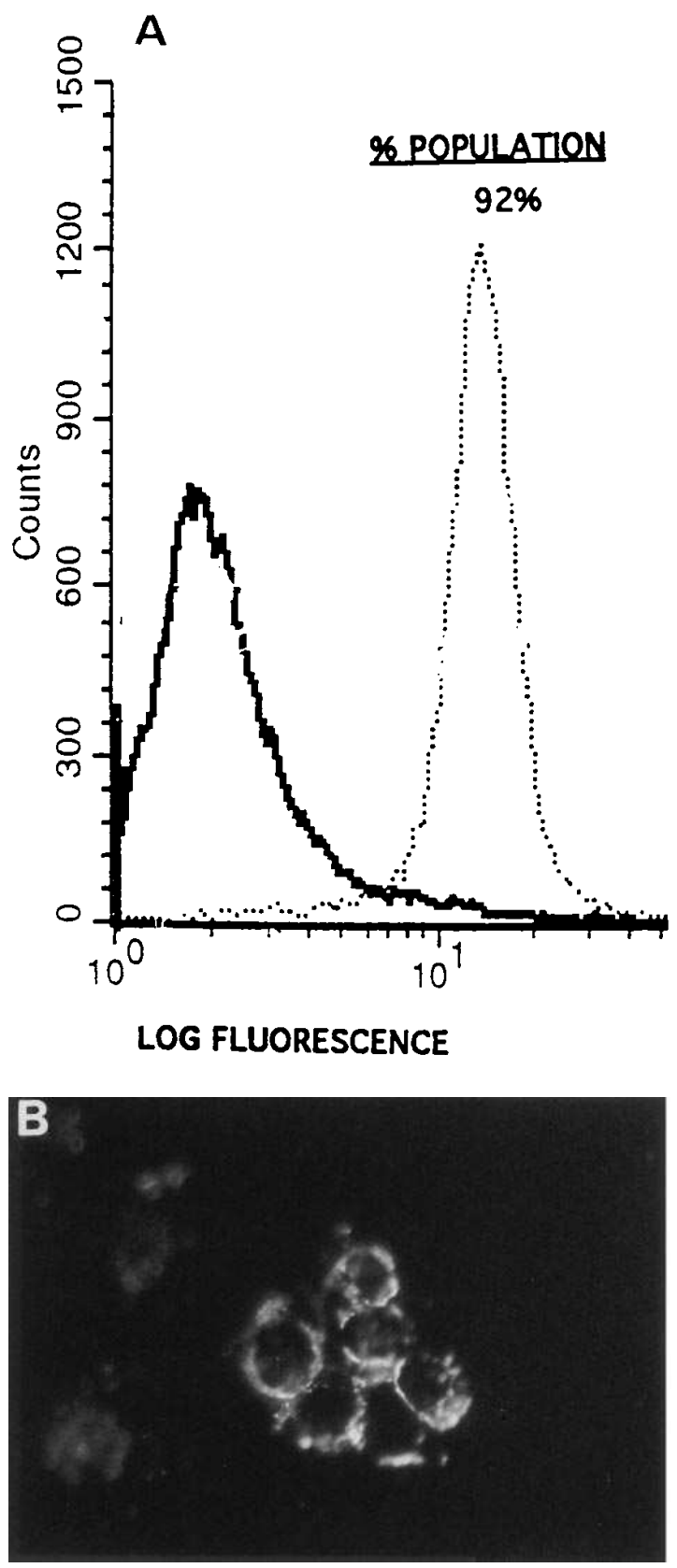

Figure 4. Immunocytochemical demonstration of iNOS in CD45-positive leukocytes. (A) FACS-sorted CD45 positive cells were used for immunofluorescence microscopy. Cell pellets from a urine of a patient with a UTI was incubated with CD45. In control cells from the same patient, the CD45 antibody was omitted. Both CD45-labeled and unlabeled cells were then labeled with fluorescein isothiocyanate labeled anti-mouse IgG and labeled and unlabeled cells sorted by flow cytometry, centrifuged onto slides $(1,200 \mathrm{rpm}, 5 \mathrm{~min})$ and fixed with acetone $\left(-20^{\circ} \mathrm{C}\right)$ for $10 \mathrm{~min}$. These CD45 cells $(B)$ were visualized for iNOS $(C)$ as outlined in the Methods section.

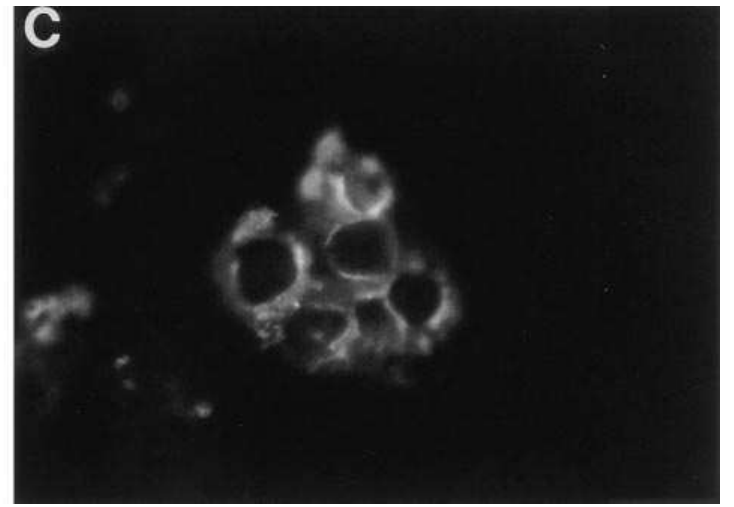

which is similar to the membrane partitioning of endothelial nitric oxide synthase (27). iNOS, eNOS, and neuronal NOS are not integral membrane proteins and do not contain stretches of hydrophobic amino acids consistent with a transmembrane domain. Cotranslational $N$-myristoylation is necessary, but not sufficient for eNOS membrane targeting (28). eNOS also is posttranslationally palmitoylated, but this modification does not contribute to the ability of eNOS to associate with biological membranes but most likely influences specific targeting to endothelial caveolae (29-31). Since iNOS is not myristoylated nor palmitoylated (25), the mechanism for its membrane assocation remains unclear. Human iNOS is localized primarily in the perinuclear region of the CD45-positive neutrophils. These data are in accord with the perinuclear localization of murine macrophage iNOS in perinuclear, post-Golgi vesicles (25). eNOS also has been localized predominantly in the perinuclear Golgi region of endothelial cells (30). The targeting of
iNOS and eNOS to the Golgi regions of cells may allow for NOS to rapidly move to post-Golgi compartments to yield higher local concentrations of NO. Alternatively, the perinuclear localization of NOS isoforms may compartmentalize the two enzymes near critical substrates or cofactors.

RT-PCR amplified both iNOS and eNOS but not neuronal NOS-specific products, and DNA sequencing confirmed the PCR results. These results are consistent with a previous report demonstrating the presence of both iNOS and eNOS RNAs in human blood borne monocytes/macrophages (15). Although eNOS mRNA is detected by RT-PCR, no eNOS protein is demonstrated in samples from patients with UTIs that are positive for human iNOS protein. This evidence, in conjunction with the calcium independence of this NOS activity demonstrates that leukocyte-derived iNOS, not eNOS, is the major source of NOS activity in the urine during infection.

This paper also demonstrates for the first time, isolation of 
Figure 5. Immunological detection and enzyme activity of iNOS after antibiotic treat-

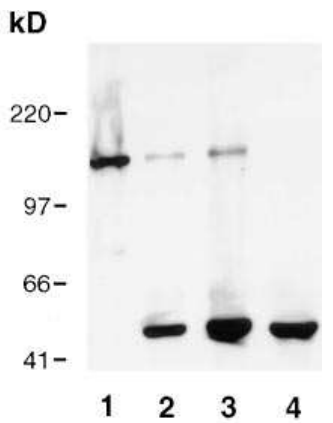

NOS Activity (pmol citrulline) $\mathrm{min} / \mathrm{mg}$ prot.) ment of UTIs. Total cell lysate $(25 \mu \mathrm{g})$ from urine of a patient with $>10^{5} \mathrm{CFU} / \mathrm{ml}$ Gardnerella vaginalis and with symptoms of urinary frequency and dysuria at time of diagnosis (lane 2), $3 \mathrm{~d}$ (lane 3), and $17 \mathrm{~d}$ (lane 4) after the initiation of antibiotic treatment. NOS activity was measured in membrane fractions prepared from each sample. Total lysate of HEK 293 cells stably transcDNA is shown in lane 1 . $\begin{array}{llll}22 & 59 & 2 & \text { fected with the human iNOS }\end{array}$ neutrophils from urine using flow cytometry of CD45-positive cells. Neutrophils are the major cell type found in the urine of most patients with UTIs, as CD14, a marker of monocytes/ macrophages, labels $<7 \%$ of the total cells. This is in agreement with other authors who find that $>90 \%$ of the cells present in urine from patients with UTIs are neutrophils (32). Therefore, we have identified human iNOS as the principal isoform of NOS found in human inflammatory neutrophils.

Previously, the expression of iNOS induced by combinations of cytokines and bacterial products was demonstrated in cultured human hepatocytes (33), chondrocytes (34), vascular smooth muscle cells (35), and megakaryocytes (36) and in rodent macrophages (37). Studies in human blood borne neutrophils $(9,38)$, in extravasated peritoneal polymorphonuclear

Table II. Detection of iNOS in Neutrophils Isolated from Urine

\begin{tabular}{|c|c|c|}
\hline & Control samples & UTI samples \\
\hline & Leukocyte $+/$ Culture - & Leukocyte+/Culture + \\
\hline & \multicolumn{2}{|c|}{ NOS-positive samples/total samples analyzed } \\
\hline NOS activity & $0 / 8$ & $21 / 23$ \\
\hline iNOS PCR product & - & $8 / 8$ \\
\hline $\begin{array}{l}\text { Western blot analysis } \\
\text { for iNOS }\end{array}$ & $0 / 8$ & $13 / 14$ \\
\hline $\begin{array}{c}\text { Immunohistochemistry of } \\
\text { neutrophils for iNOS }\end{array}$ & - & $\begin{array}{c}3 / 3 \\
(82.1 \% \text { of cells })\end{array}$ \\
\hline
\end{tabular}

16 control and 40 patients with UTIs were evaluated in this study. More than one test was performed on some patients. NADPH-dependent NOS activity values of $>5 \mathrm{pmol}$ citrulline $/ \mathrm{mg}$ protein per min were considered to represent iNOS; NADPH-dependent NOS activity values $<2$ pmol citrulline/mg protein per min were considered control levels. Two patients were negative for iNOS at the time of diagnosis. A 55yr-old female with sickle cell anemia and renal failure had little NOS activity in her urine at a time in which Enterococcus was cultured from a catherized specimen. This patient who was on immunosuppressives had repeated positive urine cultures with Klebsiella, Torulopsis, and Enterococcus and her NOS activity remained low. A 25-yr-old female was negative for both NOS activity and iNOS Western blot analysis when $E$. coli was cultured in her urine. $3 \mathrm{~d}$ after treatment, however, immunoreactivity was visualized by Western blot analysis for iNOS. leukocytes from humans with peritoneal infections (39), and in freshly isolated and cultured human monocytes/macrophages (40) failed to detect significant amounts of iNOS or NO. Recently, neutrophils within human buffy coat preparations stimulated with a mixture of interleukin-1, tumor necrosis factor $\alpha$, and interferon- $\gamma$ were shown to contain iNOS mRNA and protein, however iNOS was detected in only $20 \%$ of the stimulated neutrophils (41). Studies with monocytes/macrophages indicate that these cells can produce NO after infection with mycobacteria (17) or human immunodeficiency virus type I (42) and also after cross-linking of the surface receptor CD69 (43) or ligation of FceII/CD23 $(44,45)$. Because NO is increased under conditions where the inducing agents are undefined, the combination of microbial products and cytokines, that induces iNOS in human disease states, warrants further investigation.

During the course of a UTI, bacterial colonization causes uroepithelial cells in the bladder to rapidly secrete IL-6 (11) and IL-8 (12) and initiates a large influx of neutrophils. Neutrophil numbers can rise to $10^{3}-10^{8}$ cells $/ \mathrm{ml}$ urine in UTIs (13). We find a large increase in the NOS activity and NOS protein in these leukocytes at the time of UTI diagnosis. Since leukocyte cytoplasts can generate reactive nitrogen intermediates that kill bacteria (46) and since many UTIs resolve spontaneously, the increased NOS activity seen in urinary leukocytes from patients with UTIs may be involved in bacterial killing. Phagocytosed bacteria can be killed, perhaps by the formation of peroxynitrite, a reaction product of NO and superoxide anions. In studies with cytokine-activated blood borne neutrophils, only neutrophils that had ingested bacteria showed evidence of NOS activity as indicated by the formation of nitrotyrosine (41). While iNOS may be bactericidal, iNOS in UTIs may contribute to the inflammatory response in infection (47). Many UTI symptoms, such as dysuria and frequency, are due to the acute inflammatory response and not to the presence of the bacteria. Bacterial numbers frequently are greatly reduced within hours after initiation of antibiotic treatment (48) and yet the symptoms related to a UTI may persist for days. NOS activity and immunoreactivity persist for a period of time after initiation of antibiotic treatment, suggesting that iNOS is involved in the inflammatory response seen in UTIs. Because UTIs represent an ongoing infectious process with interplay of bacteria and host defense mechanisms, the characterization of iNOS in neutrophils from infected urine suggests an important role for $\mathrm{NO}$ as a mediator of inflammation. Measurement of iNOS in neutrophils isolated from urine may aid in diagnosis and evaluation of other inflammatory diseases such as sepsis and renal transplant rejection states.

\section{Acknowledgments}

We thank Rong Zhang and Naomi Saito for expert technical assistance, Drs. Jianwei Liu for iNOS stably transfected HEK cells, Qiaowen Xie for human iNOS primers and both Qiao-wen Xie and Wen-wen Jin for help with Western blots, David Geller and Timothy Billiar (University of Pittsburgh, Pittsburgh, PA) for the human hepatocyte iNOS cDNA, the staff of the Yale New Haven clinical microbiology lab, the nurses of the Urology section and Mark and Claire Pulkin for their help in collecting samples. iNOS specifc antibody was kindly provided by Richard Mumford and Jeffrey Weidner of Merck Laboratories.

This work was supported by National Institutes of Health grants DK 47538 and DK 09049. W.C. Sessa is an Established Investigator of the American Heart Association. 


\section{References}

1. Nathan, C., and Q.-w. Xie. 1994. Nitric oxide synthases: roles, tolls and controls. Cell. 78:915-918.

2. Hibbs, J.B., Jr. 1991. Synthesis of nitric oxide from L-arginine: a recently discovered pathway induced by cytokines with antitumour and antimicrobial activity. Res. Immunol. 142:565-569.

3. Jorens, P.G., K.E. Matthys, and H. Bult. 1995. Modulation of nitric oxide synthase activity in macrophages. Mediat. Inflamm. 4:75-89.

4. Marletta, M.A. 1994. Approaches toward selective inhibition of nitric oxide synthase J. Med. Chem. 37:1900-1907.

5. Wright, C.D., A. Mulsh, R. Busse, and H. Oswald. 1989. Generation of nitric oxide by human neutrophils. Biochem. Biophys. Res. Commun. 160:813-819.

6. Bryant, J.L., Jr., P. Mehta, A. Von der Porten, and J.L. Mehta. 1992. Copurification of $130 \mathrm{kD}$ nitric oxide synthase and a $22 \mathrm{kD}$ link from human neutrophils. Biochem. Biophys. Res. Commun. 189:558-564.

7. Ney, P., H. Schroder, and K. Schror. 1990. Nitrovasodilator-induced inhibition of LTB4 release from human PMN may be mediated by cyclic GMP. Eicosanoids. 3:243-245.

8. Van Devort, A.L., L. Yan, P.J. Madara, J.P. Cobb, R.A. Wesley, C.C. Corriveau, M.M. Tropea, and R.L. Danner. 1994. Nitric oxide regulates endotoxin induced TNF- $\alpha$ production by human neutrophils. J. Immunol. 152:41024108.

9. Yan, L., R.W. Vandivier, A.F. Suffredini, and R.L. Danner. 1994. Human polymorphonuclear leukocytes lack detectable nitric oxide synthase activity. $J$. Immunol. 153:1825-1834.

10. Smith, S.D., M.A. Wheeler, and R.M. Weiss. 1994. Nitric oxide synthase: an endogenous source of elevated nitrite in infected urine. Kidney Int. 45: 586-591.

11. Agace, W.W., S. Hedges, M. Ceska, and C. Svanborg. 1993. Interleukin-8 and the neutrophil response to mucosal gram-negative infection J. Clin. Invest. 92:780-785.

12. Hedges, S., P. Anderson, G. Liden-Janson, P. de Man, and C. Svanborg. 1991. Interleukin-6 response to deliberate Gram-negative colonization of the human urinary tract. Infect. Immun. 59:421-427.

13. Nicolle, L.E. 1994. Urinary tract infection. In Geriatric Urology. P. O'Donnell, editor, Little Brown and Co., Boston, MA. 399-411.

14. Bradford, M.M. 1976. A rapid and sensitive method for the quantitation of microgram quantities of protein utilizing the principle of protein-dye binding. Anal. Biochem. 72:248-254.

15. Reiling, N., A.J. Ulmer, M. Durchow, M. Ernst, H.-D. Flad, and S. Hauschildt. 1994. Nitric oxide synthase: mRNA expression of different isoforms in human monocytes/macrophages. Eur. J. Immunol. 24:1941-1944.

16. Laemmli, U.K. 1970. Cleavage of structural proteins during the assembly of the head of bacteriophage T4. Nature (Lond.). 227:680-685.

17. Nicholson, S., M.G. Bonecini-Almeida, J.R. Lapa e Silva, C. Nathan, Q-w. Xie, R. Mumford, J.R. Weidner, J. Calaycay, J. Geng, N. Boechat, et al. 1996. Inducible nitric oxide synthase in pulmonary alveolar macrophages from patients with tuberculosis. J. Exp. Med. 183:2293-2302.

18. Pollock, J.S., M. Nakane, L.D. Buttery, A. Martinez, D. Springall, J.M. Polak, U. Forstermann, and F. Murad. 1993. Characterization and localization of endothelial nitric oxide synthase using specific monoclonal antibodies. Am. J. Physiol. 265:C1379-C1387.

19. Nakane, M., J.S. Pollock, V. Klinghofer, F. Basha, P.A. Marsden, A. Hokari, T. Ogura, H. Esumi, and G.W. Carter. 1995. Functional expression of three isoforms of human nitric oxide synthase in baculovirus-infected insect cells. Biochem. Biophys. Res. Commun. 206:511-517.

20. McCall, T.B., N.K. Boughton-Smith, R.M.J. Palmer, B.J.R. Whittle, and S. Moncada. 1989. Synthesis of nitric oxide from L-arginine. Release and interaction with superoxide anion. Biochem. J. 261:293-296.

21. Cho, H.J., Q.-w. Xie, J. Calaycay, R.A. Mumford, K.M. Swiderek, T.D. Lee, and C. Nathan. 1992. Calmodulin is a subunit of nitric oxide synthase from macrophages. J. Exp. Med. 176:599-604.

22. Bredt, D.S., and S.H. Snyder. 1994. Nitric oxide: a physiologic messenger molecule. Annu. Rev. Biochem. 63:175-195.

23. Yui, Y., R. Hattori, K. Kosuga, H. Eizawa, K. Hiki, S. Ohkawa, K. Ohnishi, S. Terao, and C. Kawai. 1991. Calmodulin-independent nitric oxide synthase from rat polymorphonuclear neutophils. J. Biol. Chem. 266:3369-3371.

24. Stuehr, D.J., H.J. Cho, N.S. Kwon, M.F. Weise, and C.F. Nathan. 1991. Purification and characterization of the cytokine-induced macrophage nitric oxide synthase. Proc. Natl. Acad. Sci. USA. 88:7773-7777.

25. Vodovotz, Y., D. Russell, Q.-w. Xie, C. Bogdan, and C. Nathan. 1995. Vesicle membrane association of nitric oxide synthase in primary mouse macrophages. J. Immunol. 154:2914-2925.

26. Schmidt, H.H.H.W., T.D. Warner, M. Nakane, U. Forstermann, and F. Murad. 1992. Regulation and subcellular location of nitrogen oxide synthases in RAW264.7 macrophages. Mol. Pharmacol. 41:615-624.

27. Pollock, J.S., U. Forstermann, J.A. Michell, T.D. Warner, H.H. Schmidt, M. Nakane, and F. Murad. 1991. Purification and characterization of particulate endothelium-derived relaxing factor synthase from cultured and native bovine aortic endothelial cells. Proc. Natl. Acad. Sci. USA. 88:10480-10484.

28. Liu, J., and W.C. Sessa. 1994. Identification of covalently bound aminoterminal myristic acid in endothelial nitric oxide synthase. J. Biol. Chem. 269: 11691-11694.

29. Sessa, W.C., G. García-Cardeña, J. Liu, A. Keh, J.S. Pollock, J. Bradley, S. Thiru, I.M. Braverman, and K.M. Desai. 1995. The Golgi association of endothelial nitric oxide synthase is necessary for the efficient synthesis of nitric oxide. J. Biol. Chem. 270:17641-17644.

30. Liu, J., G. García-Cardeña, and W.C. Sessa. 1995. Biosynthesis and palmitoylation of endothelial nitric oxide synthase: mutagenesis of palmitoylation sites, cysteines -15 and/or -26 argues against depalmitoylation-induced translocation of the enzyme. Biochemistry. 39:12333-12340.

31. García-Cardeña, G., P. Oh, J. Liu, J.E. Schnitzer, and W.C. Sessa. 1996 Targeting of nitric oxide synthase to endothelial cell caveolae via palmitoylation: implications for nitric oxide signaling. Proc. Natl. Acad. Sci. USA. 93:64486453.

32. Katoh, S., S. Orikasa, S. Toyota, S. Itoh, K. Oikawa, Y. Fukushi, and Y Suzuki. 1991. Anti-bacterial defense mechanism of the urinary tract constructed from intestinal segments. Studies on cell population and phagocytotic activity of urinary leukocytes and bacterial growth in urine. Jap. J. Urol. 82:1436-1445.

33. Nussler, A.K., M. Di Silvio, T.R. Billiar, R.A. Hoffman, D.A. Geller, R. Selby, J. Madariaga, and R.L. Simmons. 1992. Stimulation of the nitric oxide synthase pathway in human hepatocytes by cytokines and endotoxin. J. Exp. Med. 176:261-264.

34. Palmer, R.M., M.S. Hickery, I.G. Charles, S. Moncada, and M.T. Bayliss. 1993. Induction of nitric oxide synthase in human chondrocytes. Biochem. Biophys. Res. Commun. 193:398-405.

35. Scott-Burden, T., V.B. Schini, E. Elizondo, D.C. Junquero, and P.M. Vanhoutte. 1992. Platelet-derived growth factor suppresses and fibroblast growth factor enhances cytokine-induced production of nitric oxide by cultured smooth muscle cells. Effects on cell proliferation. Circ. Res. 71:1088-1100.

36. Lelchuk, R., M.W. Radomski, J.F. Martin, and S. Moncada. 1992. Constitutive and inducible nitric oxide synthases in human megakaryoblastic cells. J. Pharmacol. Exp. Ther. 262:1220-1224.

37. Lyons, C.R., G.J. Orloff, and J.M. Cunningham. 1992. Molecular cloning and functional expression of an inducible nitric oxide synthase from a murine macrophage cell line. J. Biol. Chem. 267:6370-6374.

38. Klebanoff, S.J., and C.F. Nathan. 1993. Nitrite production by stimulated human polymorphonuclear leukocytes supplemented with azide and catalase. Biochem. Biophys. Res. Commun. 197:192-196.

39. Miles, A.M., M.W. Owens, S. Milligan, G.G. Johnson, J.Z. Fields, T.S Ing, V. Kottapalli, A. Keshavarzian, and M.B. Grisham. 1995. Nitric oxide synthase in circulating vs. extravasated polymorphonuclear leukocytes. J. Leukocyte Biol. 58:616-622.

40. Sakai, N., and S. Milstien. 1993. Availability of tetrahydrobiopterin is not a factor in the inability to detect nitric oxide production by human macrophages. Biochem. Biophys. Res. Commun. 193:378-383.

41. Evans, T.J., L.D.K. Buttery, A. Carpenter, D.R. Springall, J.M. Polak, and J. Cohen. 1996. Cytokine-treated human neutrophils contain inducible nitric oxide synthase that produces nitration of ingested bacteria. Proc Natl. Acad. Sci. USA. 93:9553-9558.

42. Bukrinsky, M.I., J.S. Nottet, H. Schmidtmayerova, L. Dubrovsky, C.R. Flanagan, M.E. Mullins, S.A. Lipton, and H.E. Gendelman. 1995. Regulation of nitric oxide synthase activity in human immunodeficiency virus type 1 (HIV-1) infected monocytes: implication for HIV-associated neurological diseases. $J$. Exp. Med. 181:735-745.

43. De Maria, R., M.G. Cifone, R. Trotta, M.R. Rippo, C. Festuccia, A Santoni, and R. Testi. 1994. Triggering of human monocyte activation through CD69, a member of the natural killer cell gene complex family of signal transducing receptors. J. Exp. Med. 180:1999-2004.

44. Mossalayi, M.D., N. Paul-Eugene, R. Ouaaz, M. Arock, J.P. Kolb, E. Kilchherr, P. Debre, and B. Dugas. 1994. Involvement of Fc epsilon RII /CD23 and L-arginine-dependent pathway in IgE-mediated stimulation of human monocyte functions. Int. Immunol. 6:931-934.

45. Vouldoukis, I., V. Riveros-Moreno, B. Dugas, F. Ouaaz, P. Becherel, P. Debre, S. Moncada, and M.D. Mossalayi. 1995. The killing of Leishmania major by human macrophages is mediated by nitric oxide induced after ligation of the Fc epsilon RII/CD23 surface antigen. Proc. Natl. Acad. Sci. USA. 92:7804-7808.

46. Malawista, S.E., R.R. Montgomery, and G. Van Blaricom. 1992. Evidence for reactive nitrogen intermediates in killing of staphylococci by human neutrophil cytoplasts. A new microbicidal pathway for polymorphonuclear leukocytes. J. Clin. Invest. 90:631-636.

47. Maskell, R., 1982. Urinary Tract Infection. Elsevier Science, New York $53 \mathrm{pp}$.

48. Gould, J.C., J.H. Bowie, and J.D.S. Cameron. 1953. Dosage of antibiotics: relationship between the in-vitro and in-vivo concentrations effective in urinary-tract infections. Lancet 264:361-364. 